\title{
Influence of a Carrington-like event on the atmospheric chemistry, temperature and dynamics
}

\author{
M. Calisto ${ }^{1}$, P. T. Verronen ${ }^{2}$, E. Rozanov ${ }^{3,4}$, and T. Peter ${ }^{4}$ \\ ${ }^{1}$ International Space Science Institute (ISSI), Bern, Switzerland \\ ${ }^{2}$ Finnish Meteorological Institute, Helsinki, Finland \\ ${ }^{3}$ Physical-Meteorological Observatory/World Radiation Center, Davos, Switzerland \\ ${ }^{4}$ Institute for Atmospheric and Climate Science ETH, Zurich, Switzerland \\ Correspondence to: M. Calisto (marco.calisto@ issibern.ch)
}

Received: 1 May 2012 - Published in Atmos. Chem. Phys. Discuss.: 8 June 2012

Revised: 4 September 2012 - Accepted: 16 September 2012 - Published: 26 September 2012

\begin{abstract}
We have modeled the atmospheric impact of a major solar energetic particle event similar in intensity to what is thought of the Carrington Event of 1-2 September 1859. Ionization rates for the August 1972 solar proton event, which had an energy spectrum comparable to the Carrington Event, were scaled up in proportion to the fluence estimated for both events. We have assumed such an event to take place in the year 2020 in order to investigate the impact on the modern, near future atmosphere. Effects on atmospheric chemistry, temperature and dynamics were investigated using the 3-D Chemistry Climate Model SOCOL v2.0. We find significant responses of $\mathrm{NO}_{\mathrm{x}}, \mathrm{HO}_{\mathrm{x}}$, ozone, temperature and zonal wind. Ozone and $\mathrm{NO}_{\mathrm{x}}$ have in common an unusually strong and long-lived response to this solar proton event. The model suggests a 3-fold increase of $\mathrm{NO}_{\mathrm{x}}$ generated in the upper stratosphere lasting until the end of November, and an up to 10 -fold increase in upper mesospheric $\mathrm{HO}_{\mathrm{x}}$. Due to the $\mathrm{NO}_{\mathrm{x}}$ and $\mathrm{HO}_{\mathrm{x}}$ enhancements, ozone reduces by up to 60 $80 \%$ in the mesosphere during the days after the event, and by up to $20-40 \%$ in the middle stratosphere lasting for several months after the event. Total ozone is reduced by up to $20 \mathrm{DU}$ in the Northern Hemisphere and up to $10 \mathrm{DU}$ in the Southern Hemisphere. Free tropospheric and surface air temperatures show a significant cooling of more than $3 \mathrm{~K}$ and zonal winds change significantly by $3-5 \mathrm{~m} \mathrm{~s}^{-1}$ in the UTLS region. In conclusion, a solar proton event, if it took place in the near future with an intensity similar to that ascribed to of the Carrington Event of 1859, must be expected to have a major impact on atmospheric composition throughout the middle atmosphere, resulting in significant and persistent decrease in total ozone.
\end{abstract}

\section{Introduction}

Solar energetic particle events, frequently referred to solar proton events (SPEs), occur when protons and other particles emitted by the active Sun are accelerated to very high energies (for protons up to $500 \mathrm{MeV}$ ) either close to the Sun's surface during a solar flare or in interplanetary space by magnetic shock waves associated with coronal mass ejections (Reames, 1999). They typically last for a few days. The high energy protons are deflected, when they enter the Earth's magnetic field, and upon penetrating the atmosphere can cause massive ionization including significant production of $\mathrm{HO}_{\mathrm{x}}$ and $\mathrm{NO}_{\mathrm{x}}$ (Seppälä et al., 2004; Jackman et al., 2009).

Solar protons normally have energies that are insufficient to make them enter deep into the Earth's magnetic field. However, during unusually strong solar flares, protons may assume kinetic energies sufficiently high to penetrate deeper into the Earth's magnetosphere and ionosphere especially at the poles, where the magnetic field lines cut across pressure levels and dive deep into the atmosphere towards the surface. Energetic protons that are guided by the magnetic field into the polar regions collide with atmospheric constituents and gradually transfer their kinetic energy into potential energy through the process of ionization of the air constituents. For example, the protons can ionize air molecules, $X_{2}+p \rightarrow X_{2}^{+}+p+e *$, producing fast secondary electrons $(X=\mathrm{N}, \mathrm{O}$, and the star symbolizes high kinetic energy). These electrons can dissociate the nitrogen molecule, producing both, the electronic ground state and the electronic 
first excited state of the nitrogen atom. The latter reacts readily with $\mathrm{O}_{2}$, producing nitric oxide, $\mathrm{N}\left({ }^{2} \mathrm{D}\right)+\mathrm{O}_{2} \rightarrow \mathrm{NO}+\mathrm{O}$.

Below the mesopause, where water cluster ions form, the ionization through the solar protons contributes also to the formation of $\mathrm{HO}_{\mathrm{x}}$ radicals. For example, molecular oxygen ions $\left(\mathrm{O}_{2}^{+}\right)$produced by an SPE form $\mathrm{O}_{4}^{+}$ions via attachment of molecular oxygen, which then react with water. This hydrated ion quickly hydrates further to produce $\mathrm{OH}$ via $\mathrm{O}_{2}^{+} \cdot \mathrm{H}_{2} \mathrm{O}+\mathrm{H}_{2} \mathrm{O} \rightarrow \mathrm{H}_{3} \mathrm{O}^{+} \cdot \mathrm{OH}+\mathrm{O}_{2} \rightarrow \mathrm{H}_{3} \mathrm{O}^{+}+\mathrm{OH}+\mathrm{O}_{2}$.

Analyses of ice core samples have indicated that the Carrington flare of 1859 might have been the largest event observed in the past $500 \mathrm{yr}$ (McCracken et al., 2001). However, a recent study casts serious doubts on the existence of clear evidence for this event in most of the available ice core nitrate records (Wolff et al., 2012). Subsequently we assume an event with a $>30 \mathrm{MeV}$ proton fluence of $1.9 \times 10^{10} \mathrm{~cm}^{-2}$, similar what had been assumed about the 1859 Carrington Event (McCracken et al., 2001; Smart et al., 2006). The influence of such solar proton events - in this study termed Carrington-like events - on atmospheric chemistry have been assessed by several authors, see recently Thomas et al. (2007) and Rodger et al. (2008). Thomas et al. (2007) were using the Goddard Space Flight Center two-dimensional atmospheric model. For the calculations, they scaled the solar proton event from 1989 to match to the flux of the 1859 SPE. The duration of the ionization applied by Thomas et al. (2007) is 2 days. They demonstrated that ozone is sensitive to the additional $\mathrm{NO}_{\mathrm{x}}$ source in the atmosphere, such that two months after the event the ozone reduction at about $40 \mathrm{~km}$ still exceeds $30 \%$ in both hemispheres.

Rodger et al. (2008) used a 1-D combined ion and neutral chemistry model, studying the effects on ionosphere and atmosphere. They showed that a Carrington-like event could result in an unusually strong and long lived $\mathrm{O}_{\mathrm{x}}$ decrease (levels drop by $\sim 40 \%$ ) in the upper stratosphere. Additionally, they demonstrated that such an event would cause disruption of HF communications, but this effect was found not to be significantly larger than those caused by other major SPEs.

With this study we want to focus on solar proton events that are as significant as the Carrington event has been, but we ask what atmospheric effects such an event would have if it happened in the near future. We assume conditions for the atmosphere expected in the year 2020 (with chlorine concentrations already at somewhat lower levels than nowadays). This approach is further motivated by Barnard et al. (2011), who argue that the number of large SPEs will likely be enhanced throughout the next years. Our goal is to analyze changes in the atmospheric chemistry, temperature and dynamics. In contrast to the 1-D and 2-D models mentioned in the previous paragraphs, we employ for the first time a 3-D Chemistry Climate Model (CCM). The CCM describes the entire chain of physical and chemical processes in the middle atmosphere, i.e. stratosphere and mesosphere, including changes in atmospheric dynamics that are not resolved in 1$\mathrm{D}$ or 2-D models. The specific model applied here (SOCOL) and the numerical setup are described in Sect. 2, and Sects. 3 and 4 provide the results and a discussion, respectively.

\section{Model description and experimental setup}

The CCM SOCOL is a combination of the Global Circulation Model (GCM) MA-ECHAM4 and the chemistry-transport model MEZON. MA-ECHAM4 (Manzini et al., 1997), the middle atmosphere version of ECHAM4, is a spectral model with T30 horizontal truncation resulting in a grid spacing of about $3.75^{\circ}$. It has 39 levels in the vertical direction in a hybrid sigma-pressure coordinate system spanning the model atmosphere from the surface to $0.01 \mathrm{hPa}(\sim 80 \mathrm{~km}$ altitude).

The chemistry-transport model MEZON (Rozanov et al., 1999; Egorova et al., 2003) has the same vertical and horizontal resolution and treats 41 chemical species within the oxygen, hydrogen, nitrogen, carbon, chlorine and bromine groups, which are determined by 140 gas-phase reactions, 46 photolysis reactions and 16 heterogeneous reactions in/on aqueous sulfuric acid aerosols and polar stratospheric clouds at high latitudes, namely water ice, nitric acid trihydrate and ternary supercooled solutions $\left(\mathrm{HNO}_{3}-\mathrm{H}_{2} \mathrm{SO}_{4}-\mathrm{H}_{2} \mathrm{O}\right)$.

The original version of the CCM SOCOL was described and evaluated by Egorova et al. (2005) and compared with other models by Eyring et al. (2006, 2007). Several model deficiencies in the chemical-transport part have been revised by the development of the CCM SOCOLv2.0, which is used in the current work. The new features and the evaluation of SOCOLv2.0 are presented by Schraner et al. (2008).

In this paper we approximate the properties of the Carrington Event by an up-scaling of the August 1972 SPE, which we use as a reference event. Comparing the Carrington event ionization rates to other SPEs, e.g. the October 2003 SPE, which is one of the largest SPEs recorded and for which we have the ionization rates readily available (Verronen et al., 2005), we find that at $35-60 \mathrm{~km}$ the total ionization rates of the Carrington event are 4-4.5 times higher than those of October 2003. This number is similar to the scaling factor used by Thomas et al. (2007), although they used a different SPE. Above $80 \mathrm{~km}$ and below $30 \mathrm{~km}$, ionization rates for the Carrington event are smaller than those of October 2003, which is due to the different particle energy spectra during these two events.

Cosmogenic isotope concentrations (such as ${ }^{10} \mathrm{Be}$ in ice cores) suggest that the Carrington Event had a soft energy spectrum, similar to the SPE from August 1972 (Smart et al., 2006), and can be described using the Weibull distribution (Rodger et al., 2008). In order to model the Carrington event, we adopted the altitude dependent ionization rates (IR) from Rodger et al. (2008), which were calculated using a method utilizing energy-range relationships for protons (Verronen et al., 2005). The ionization due to electrons and $\alpha$ particles has been neglected, as their contribution, compared to that of the protons, is small (Rodger et al., 2008; Funke et al., 2011). 
The CCM SOCOL has no explicit treatment of ion chemistry. Therefore, it is necessary to convert the ionization rates in an approximate manner into $\mathrm{NO}_{\mathrm{x}}$ and $\mathrm{HO}_{\mathrm{x}}$ production rates.

The energetic protons in an SPE can ionize air molecules, $X_{2}+p \rightarrow X_{2}^{+}+p+e *$, producing fast secondary electrons ( $X=\mathrm{N}, \mathrm{O}$, and the star symbolizes high kinetic energy). These electrons can dissociate the nitrogen molecule, $\mathrm{N}_{2}+$ $e * \rightarrow 2 \mathrm{~N}\left({ }^{4} \mathrm{~S} ;{ }^{2} \mathrm{D}\right)+e$, where $\mathrm{N}\left({ }^{4} \mathrm{~S}\right)$ is the electronic ground state of the nitrogen atom and $N\left({ }^{2} \mathrm{D}\right)$ is its electronic first excited state. Almost all of the $\mathrm{N}\left({ }^{2} \mathrm{D}\right)$ atoms react with $\mathrm{O}_{2}$, producing nitric oxide, $\mathrm{N}\left({ }^{2} \mathrm{D}\right)+\mathrm{O}_{2} \rightarrow \mathrm{NO}+\mathrm{O}$ (whereas collisional quenching of $\mathrm{N}\left({ }^{2} \mathrm{D}\right)$ plays only a minor role). Conversely, the ground state can undergo a "cannibalistic" reaction with $\mathrm{NO}, \mathrm{N}\left({ }^{4} \mathrm{~S}\right)+\mathrm{NO} \rightarrow \mathrm{N}_{2}+\mathrm{O}$, leading to the destruction of $\mathrm{NO}_{\mathrm{x}}$. Therefore, within SOCOL N($\left.{ }^{2} \mathrm{D}\right)$ is immediately converted into $\mathrm{NO}$, while $\mathrm{N}\left({ }^{4} \mathrm{~S}\right)$ is a regular species in the CCM, which is subject to a full kinetic treatment. Following Brasseur and Solomon (2005), when dissociation of molecular nitrogen yields one $\mathrm{N}\left({ }^{4} \mathrm{~S}\right)$ and one $\mathrm{N}\left({ }^{2} \mathrm{D}\right)$ atom, the net odd nitrogen production is extremely small: almost every $\mathrm{N}\left({ }^{2} \mathrm{D}\right)$ atom produces one $\mathrm{NO}$ molecule, but almost every $\mathrm{N}\left({ }^{4} \mathrm{~S}\right)$ atom immediately destroys one at these altitudes. Net production is provided only by the very small fraction of $\mathrm{N}\left({ }^{4} \mathrm{~S}\right)$ atoms which react with oxygen, $\mathrm{N}\left({ }^{4} \mathrm{~S}\right)+\mathrm{O}_{2} \rightarrow \mathrm{NO}+$ $\mathrm{O}$, rather than with NO.

Therefore, a reliable quantification of the $N\left({ }^{2} \mathrm{D}\right): \mathrm{N}\left({ }^{4} \mathrm{~S}\right)$ branching ratio is required. Following Porter et al. (1976), $1.25 \mathrm{~N}$ molecules are produced per ion pair, of which $55 \%$ are $\mathrm{N}\left({ }^{2} \mathrm{D}\right)$ and $45 \%$ are $\mathrm{N}\left({ }^{4} \mathrm{~S}\right.$ ) (see Table $\mathrm{V}$ in Porter et al., 1976). In SOCOL, the first excited state, $\mathrm{N}\left({ }^{2} \mathrm{D}\right)$, is assumed to convert instantaneously to NO. It is important to note that in the model used in this paper, the ground state atom, $\mathrm{N}\left({ }^{4} \mathrm{~S}\right)$, may undergo the cannibalistic reaction with the produced NO, i.e. $\mathrm{N}\left({ }^{4} \mathrm{~S}\right)+\mathrm{NO} \rightarrow \mathrm{N}_{2}+\mathrm{O}$, or may react, though much more slowly, with molecular oxygen to generate NO. The production of $\mathrm{HO}_{\mathrm{x}}$ by proton precipitation has been taken into account using the calculations by Solomon et al. (1981). They showed that below $60 \mathrm{~km}$ altitude about $2 \mathrm{HO}_{\mathrm{x}}$ molecules are produced, drops towards $1.2 \mathrm{HO}_{\mathrm{x}}$ at $80 \mathrm{~km}$, and a much smaller amount above about $85 \mathrm{~km}$. Egorova et al. (2011) showed that the $\mathrm{NO}_{\mathrm{x}}$ and $\mathrm{HO}_{\mathrm{x}}$ parameterizations used in our study compare reasonably well with their model using complete ion chemistry.

Here, we have implemented the influence of the August 1972 SPE, scaled to the Carrington event in September 1859, into the 3-D CCM SOCOL v2.0. We then carried out two 9-month long runs - a control run and a perturbed Carrington run - with 10 ensemble members each and starting with atmospheric conditions in August 2020 and ending in April 2021. The ensemble members were generated by small $(-0.1 \ldots+0.1 \%)$ perturbations of the $\mathrm{CO}_{2}$ mixing ratio during the first month of the model run. This corresponds to simulating the impact on an atmosphere with a total halogen burden slightly lower than today and a global average total ozone distribution, which has continued to recover compared to the most recent values in an atmosphere with maximum halogen loading. Both model experiments are driven with prescribed sea surface temperature (SST) and Sea Ice.

\section{Results}

The ionization rates taken from Rodger et al. (2008), who combined a spectral form of the August 1972 SPE (their Fig. 1) with the time behavior of the $>30 \mathrm{MeV}$ fluxes (their Fig. 2, top) applied in the present study are shown in Fig. 1.

It suggests that the major fraction of the energy is deposited in the mesosphere (around $50-80 \mathrm{~km}$ in altitude), and only very little penetrates to altitudes lower than $20 \mathrm{~km}$. The application of the characteristics of the August 1972 SPE results in two distinct ionization peaks, with the second peak in the beginning of September being more intense than the first one at the end of August. This procedure suggests that there is hardly any penetration of the signal into the troposphere, which means that the event is unlikely to produce a nitrate spike in the ice core records. If correct, this deprives us of using ice core nitrate as a potent indicator of such events (Wolff et al., 2012). However, Vitt et al. (2000) suggest, that an increase of odd nitrogen in the stratosphere could be transported to the ground via either stratosphere/troposphere exchange or denitrification through polar stratospheric clouds. Therefore, it cannot be ruled out, that this solar proton event was able producing a nitrate spike in the ice core records even if this nitrate spike is made through stratosphere/troposphere exchange or denitrification and not by direct ionization in the troposphere.

Rusch et al. (1981) show ionization rates for the 1972 SPE which have a peak ionization rate $>40000 \mathrm{~cm}^{-3} \mathrm{~s}^{-1}$ compared to our peak rate of $>25000 \mathrm{~cm}^{-3} \mathrm{~s}^{-1}$. However, our Fig. 1 displays daily average values that are naturally smaller than those given in a finer time resolution by Rusch et al. (1981) in their Fig. 4. Our IR, which are originally calculated with a 5-min resolution show peak ionization rates reaching $100000 \mathrm{~cm}^{-3} \mathrm{~s}^{-1}$ around $50 \mathrm{~km}$, which means that they are about 2.5 times higher than the peak values given by Rusch et al. (1981) for the August 1972 SPE.

Figures 2-5 show time series of zonal mean ensemble responses in $\mathrm{NO}_{\mathrm{x}}, \mathrm{HO}_{\mathrm{x}}$, ozone and temperature calculated as a relative deviation of the experimental run from the reference run in the polar regions $\left(70-90^{\circ}\right)$. Figures $6-7$ show ensemble mean changes in zonal wind and total ozone for the Northern and Southern Hemisphere ( $\mathrm{NH}$ and $\mathrm{SH}$ ) from $\mathrm{Au}-$ gust to November and September to November, respectively. Whereas Fig. 8 is showing ensemble mean changes for sea level pressure for the NH starting day 211 until day 311.

The results show that the $\mathrm{NO}_{\mathrm{x}}$ enhancement after this event lasts for weeks due to the longevity of these species at these altitudes. The simulated $\mathrm{NO}_{\mathrm{x}}$ increase exceeds $300 \mathrm{ppbv}$ in the SH and $200 \mathrm{ppbv}$ in the NH (Fig. 2). The 


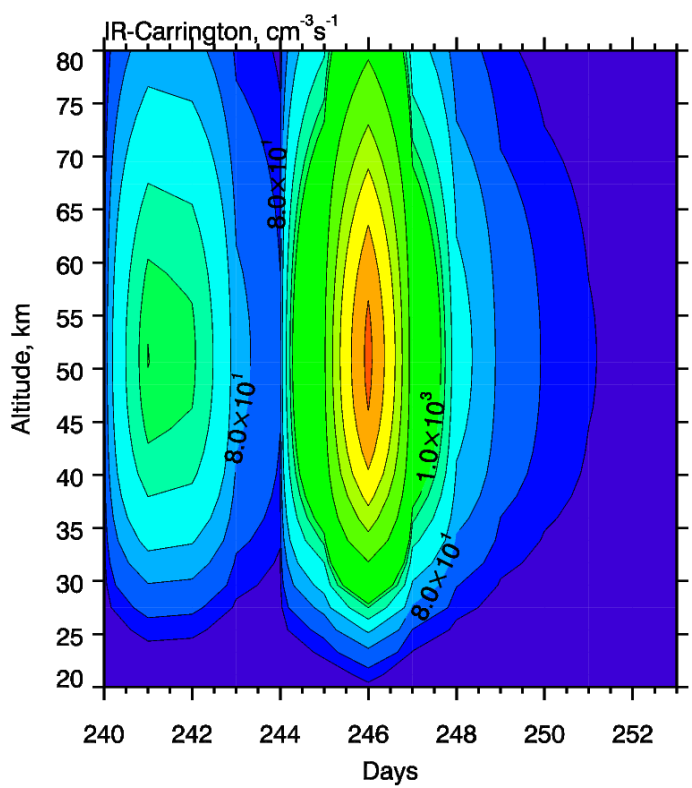

Fig. 1. Height versus time evolution of ionization rates for the investigated Carrington-like solar proton event. The particular shape with two major episodes within 5 days is taken from the event of August 1972. Contour levels: 0, 5, 20, 80, 200, 500, 800, 1000, 4000, 8000, $12000,18000,25000,30000$ ion pairs $\mathrm{cm}^{-3} \mathrm{~s}^{-1}$.

Southern Hemisphere displays a stronger $\mathrm{NO}_{\mathrm{x}}$ perturbation because the event is assumed to take place on 1-2 September, when the Northern Hemisphere is still exposed to more sunlight. This difference in sunlight supports the cannibalistic reaction for odd nitrogen, i.e. $\mathrm{NO}+h v \rightarrow \mathrm{N}\left({ }^{4} \mathrm{~S}\right)+\mathrm{O} ; \mathrm{N}\left({ }^{4} \mathrm{~S}\right)$ $+\mathrm{NO} \rightarrow \mathrm{N}_{2}+\mathrm{O}$ (Crutzen and Brühl, 1996). This reaction in combination with the still prevailing southerly phase of the Brewer-Dobson circulation is responsible for the less intense increase in $\mathrm{NO}_{\mathrm{x}}$ in the Northern Hemisphere in Fig. 2. It should be noted that zonal asymmetry of the odd nitrogen response to the Carrington event is negligible compared to the changes in meridional direction. The zonal asymmetry goes up to a maximum of $5 \%$ in the Northern and Southern Hemispheres (figure not shown).

The computed increase in $\mathrm{NO}_{\mathrm{x}}$ does not agree with the 1D model results of Rodger et al. (2008), presumably because of highly simplified dynamics and transport in their model, whereas the 2-D model used by Thomas et al. (2007) is in good qualitative agreement.

The upper panel in Fig. 3 shows an increase for $\mathrm{HO}_{\mathrm{x}}$ in the Northern Hemisphere of approximately $10 \mathrm{ppbv}$ or up to $200 \%$ from $70 \mathrm{~km}$ to the model top. A higher increase of up to $15 \mathrm{ppbv}$ or $1000 \%$ from $70 \mathrm{~km}$ to the model top is computed for the Southern Hemisphere. The reason that the increase appears to be more significant in the Southern Hemisphere is again related to the phase of the Brewer-Dobson circulation and to the higher illumination of the Northern Hemi-
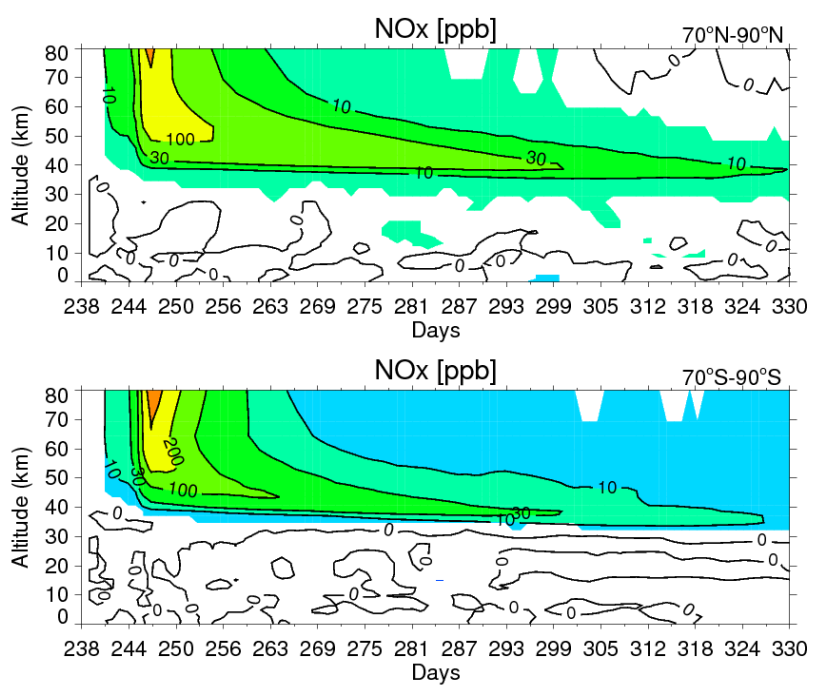

Fig. 2. Upper panel: evolution of changes in $\mathrm{NO}_{\mathrm{x}}$ zonal mean mixing ratio profile in the polar regions $\left(70-90^{\circ} \mathrm{N}\right)$. Lower panel: same for $70-90^{\circ} \mathrm{S}$. Colors indicate areas with at least $95 \%$ statistical significance. Upper panel contour levels: 10, 30, 100, 200 ppbv. Contour levels lower panel: 10, 20, 200, 300 ppbv.
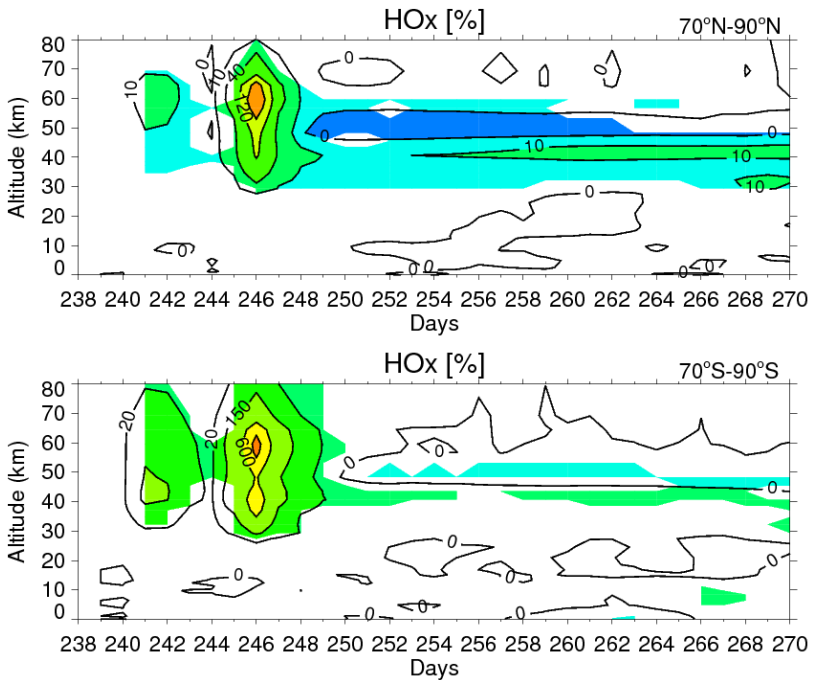

Fig. 3. Upper panel: evolution of changes in $\mathrm{HO}_{\mathrm{x}}$ zonal mean mixing ratio profile in the polar region $\left(70-90^{\circ} \mathrm{N}\right)$ in percent. Lower panel: same for $70-90^{\circ} \mathrm{S}$. Colors indicate areas with at least $95 \%$ statistical significance. Contour levels for upper panel: $-20,0,50$, $150,300 \%$. Contour levels for lower panel: $-20,0,50,250,700$, $1000 \%$.

sphere, i.e. the background level of $\mathrm{HO}_{\mathrm{x}}$ is larger (Rodger et al., 2008).

Due to cannibalistic reactions such as $\mathrm{OH}+\mathrm{HO}_{2} \rightarrow \mathrm{H}_{2} \mathrm{O}$ $+\mathrm{O}_{2}$ the odd hydrogen species are less long-lived than $\mathrm{NO}_{\mathrm{x}}$, so that the significance of the impact on $\mathrm{HO}_{\mathrm{x}}$ is of shorter duration, basically lasting only during the time when the solar protons are penetrating the atmosphere. 


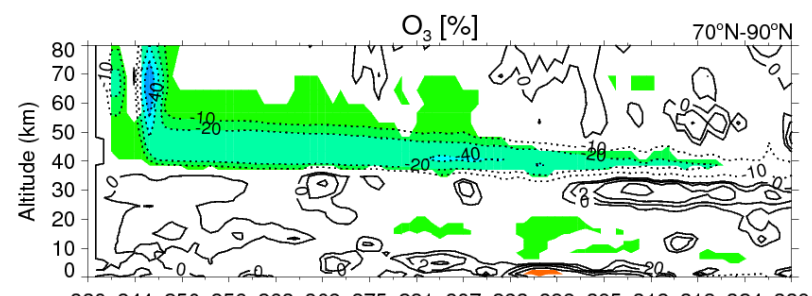

238244250256263269275281287293299305312318324330 Days

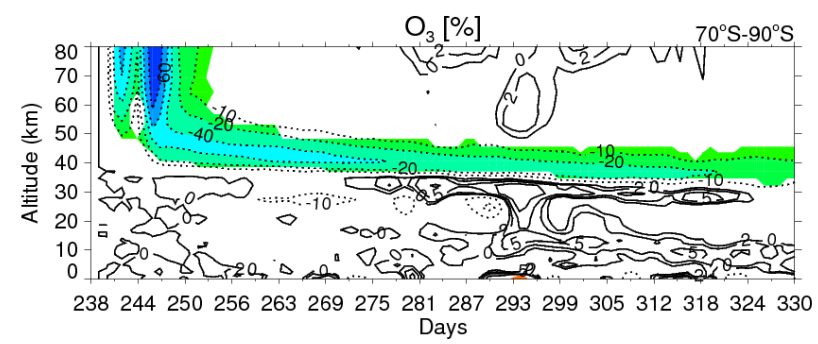

Fig. 4. Upper panel: evolution of changes in ozone zonal mean mixing ratio profile in the polar region $\left(70-90^{\circ} \mathrm{N}\right)$ in percent. Lower panel: same for $70-90^{\circ} \mathrm{S}$. Colors indicate areas with at least $95 \%$ statistical significance. Contour levels: $-100,-80,-60,-40,-20$, $-10,0,2,5,10,50 \%$.

Highly significant decreases of ozone are predicted for the upper and middle stratosphere with losses of about $80 \%$ and $60 \%$ in the Southern and Northern Hemisphere, respectively (Fig. 4). These losses are strongly correlated to the major increases in $\mathrm{NO}_{\mathrm{x}}$ and $\mathrm{HO}_{\mathrm{x}}$ shown in Figs. 2 and 3 causing the destruction of the ozone extending from $80 \mathrm{~km}$ all the way down to $30 \mathrm{~km}$. Below the depleted layer there is some indication of self-healing of ozone in the lower stratosphere. There is a direct response in temperature following these ozone perturbations. The depletion in ozone leads to a decrease in solar heating in the sunlit atmosphere, which is visible in the upper panel in Fig. 5 for the NH shortly after the event has started. The model shows a significant cooling of up to $3 \mathrm{~K}$ at about $60 \mathrm{~km}$. Conversely the $\mathrm{SH}$, though showing a stronger response in $\mathrm{NO}_{\mathrm{x}}, \mathrm{HO}_{\mathrm{x}}$ and $\mathrm{O}_{3}$, develops a less intense cooling because of the initially lower insolation, whereas a stronger and significant response appears only long after the impact, namely in mid-November when the solar UV irradiating in the SH has increased significantly. However, overall the impact is similar in both hemispheres with an average decrease on the order of $1 \mathrm{~K}$ in the upper stratosphere/lower mesosphere. This SPE-induced polar cooling increases the equator-pole temperature gradient with repercussions for zonal winds. Figure 6 shows the changes in zonal winds averaged from August to November for the Northern and the Southern Hemispheres at $25 \mathrm{hPa}$ (middle stratosphere; upper panel) and at $63 \mathrm{hPa}$ (lower stratosphere; lower panel). Both altitude levels show in the $\mathrm{NH}$ an increase of up to $3 \mathrm{~m} \mathrm{~s}^{-1}$ in the region of the polar vortex. The acceleration of the zonal wind is explained by the cooling of the polar upper stratosphere due to the polar ozone depletion in-
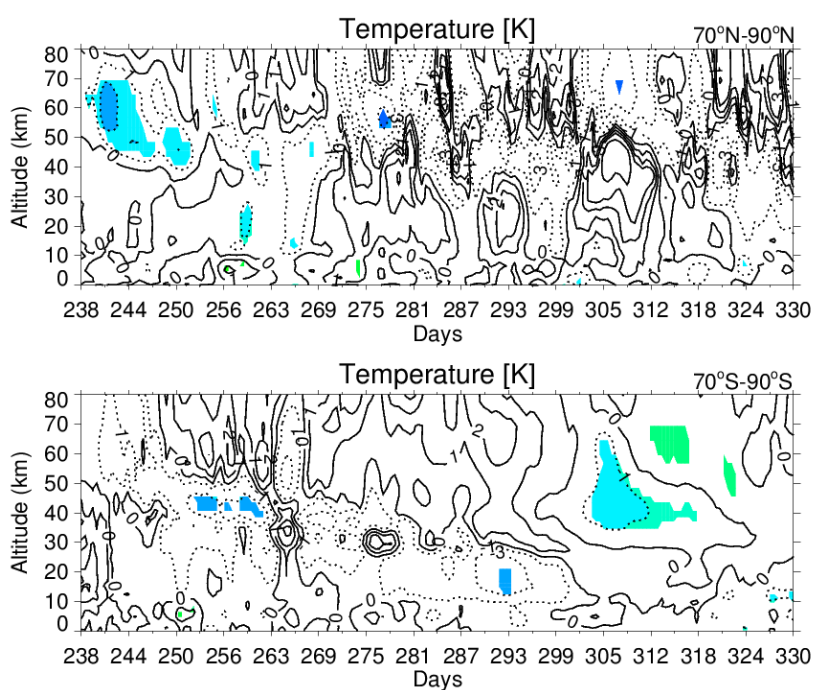

Fig. 5. Upper panel: evolution of changes in zonal mean temperature profile for the polar region $\left(70-90^{\circ} \mathrm{N}\right)$ in Kelvin. Lower panel: same for $70-90^{\circ} \mathrm{S}$. Colors indicate areas with at least $95 \%$ statistical significance. Contour levels: $-10,-6,-3,-1,0,1,2,3,5$, $10 \mathrm{~K}$.
$\mathrm{NH}$
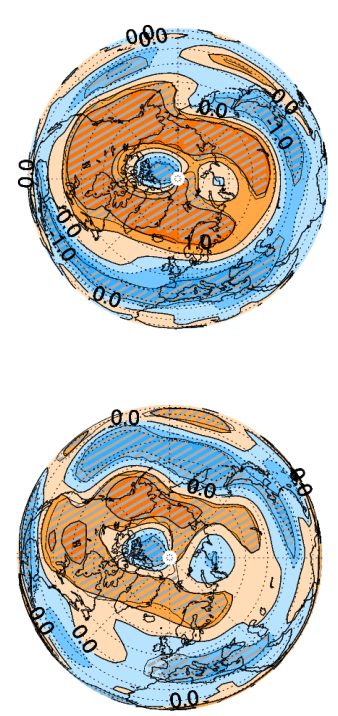

$\mathrm{SH}$
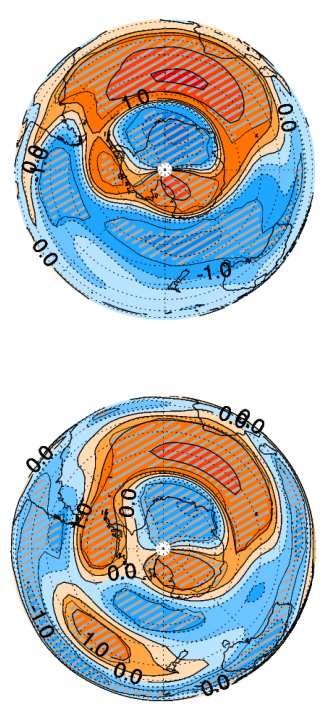

$[\mathrm{m} / \mathrm{s}]$

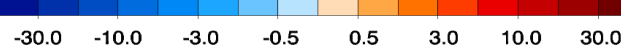

Fig. 6. Upper row: polar stereographic projection of zonal wind changes at $25 \mathrm{hPa}$ from August to November given in $\mathrm{m} \mathrm{s}^{-1}$. Lower row: zonal wind changes at $63 \mathrm{hPa}$ from August to November given in $\mathrm{m} \mathrm{s}^{-1}$. Left column: NH. Right column: SH. Hatched areas show $95 \%$ statistical significance. 


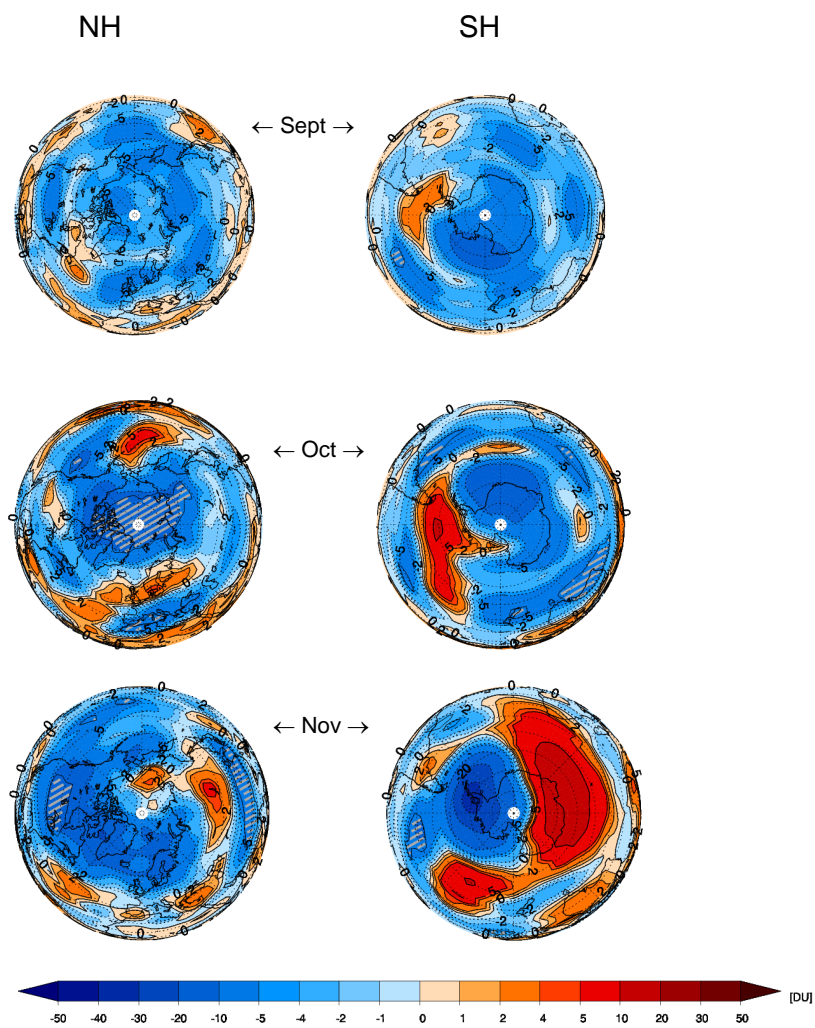

Fig. 7. Left column: polar stereographic projection of changes in total ozone (in DU) for the NH from September to November resulting from the Carrington-like event. Right column: same for the SH. Hatched areas show $95 \%$ statistical significance.

duced by the SPE, leading to an acceleration of the zonal wind in agreement with the thermal wind balance (Limpasuvan et al., 2005). The SH shows a similar pattern to the $\mathrm{NH}$ but the increase in speed reaches up to $5 \mathrm{~m} \mathrm{~s}^{-1}$. The reason for this hemispheric asymmetry in zonal winds is in accordance with the asymmetries in temperatures (compare Fig. 5).

The effects of the Carrington-like event on total ozone in both hemispheres are displayed in Fig. 7. Total ozone is reduced by a maximum of about $20 \mathrm{DU}$ in October in the $\mathrm{NH}$ and about $10 \mathrm{DU}$ in the autumn SH. These maximum total ozone changes are not predicted to occur during the time when the SPE is happening; rather, the transport of the enhanced $\mathrm{NO}_{\mathrm{x}}$ to lower altitudes and therefore higher ozone amounts allows a more substantial total ozone impact. The collar like pattern from September to November in the NH and from September to October in the SH is due to the acceleration of both polar jet streams. In November, when the polar vortex in the SH breaks up, air from the lower latitudes which was less affected by $\mathrm{NO}_{\mathrm{x}} / \mathrm{HO}_{\mathrm{x}}$ perturbations and ozone depletion enters the polar region (lowermost right panel).
The changes in sea level pressure for the Northern Hemisphere, given in $\mathrm{Pa}$, are depicted in Fig. 8. It is shown that a solar proton event similar to the Carrington event can cause an increase in the sea level pressure of more than $200 \mathrm{~Pa}$. This increase in pressure, although not significant over the whole region, can be used as a proxy for the changes in the Arctic Oscillation which in turn can alter the surface air temperature shown in the last figure.

Finally, we investigate the influence of this major solar proton event on the surface air temperature (SAT) and its connection to the Arctic Oscillation. The left and right panels in Fig. 9 show the November monthly mean SAT for the NH and SH, respectively. The northern hemispheric plot shows a significant decrease of up to $5 \mathrm{~K}$ over the eastern part of Europe and Russia. A smaller decrease of about $3 \mathrm{~K}$ is depicted for the Southern Hemisphere over Argentina. These changes in SAT are caused by an intensification of the polar vortex, which in the NH is known as positive phase of Arctic Oscillation (Thompson and Wallace, 1998). The decrease over Argentina is caused by a change to a negative Southern Annular Mode giving warmer temperatures over Antarctica and colder temperatures over Argentina (Arblaster and Meehl, 2005).

\section{Discussion and conclusion}

This work presents simulations of the impact of a major Solar Proton Event (SPE) on a near-future atmosphere. The simulation assumes an event similar to the August 1972 SPE, but scaled up in strength to the Carrington Event from 1859. Effects on atmospheric chemistry, temperature and dynamics are investigated. The total fluence of energies $>30 \mathrm{MeV}$ was scaled to match the value given by Smart et al. (2006), as identified through impulsive nitrate events in the ice core. The IR was calculated as described by Verronen et al. (2005) up to $0.01 \mathrm{hPa}$.

From the results presented in Sect. 3 we draw the following conclusions. The influence of the Carrington-like event on the chemistry and dynamics consists of $\mathrm{NO}_{\mathrm{x}}$ and $\mathrm{HO}_{\mathrm{x}}$ enhancement, depletion of ozone mixing ratios and total ozone column, cooling in the polar mesosphere and upper stratosphere, an acceleration of the zonal winds in both polar jets, and finally statistically significant imprints on surface air temperatures. Except for temperature in the SH middle atmosphere, changes due to the SPE are most pronounced shortly after the event happened.

The modeled impact on $\mathrm{NO}_{\mathrm{x}}, \mathrm{HO}_{\mathrm{x}}$ and ozone is in reasonable agreement with the results of Thomas et al. (2007). Our results show a similar impact pattern compared to Rodger et al. (2008), i.e. the SH showing a larger response to the SPE than the NH. A difference concerning the longevity of the impact becomes apparent, which is due to the fact that we use a 3-D model with comprehensive transport and dynamics implementation. Regarding the longevity of the impact, 


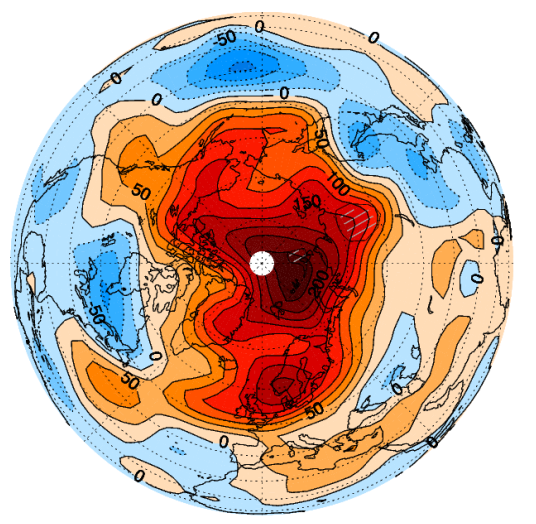

$\begin{array}{lllllllllllllllllll}-.225 & -200 & -175 & -150 & -125 & -100 & -75 & -50 & -25 & 0 & 25 & 50 & 75 & 100 & 125 & 150 & 175 & 200 & 225\end{array}$

Fig. 8. Polar stereographic projection of changes in sea level pressure for the NH for day 211 to 311 resulting from the Carringtonlike Event. Hatched areas show $95 \%$ statistical significance.

Thomas et al. (2007) show for ozone and the nitrogen species that after 2 months the depletion is still significant, which is also true for our results.

Comparing the outcome for temperature and dynamics modeled with SOCOL with results of Jackman et al. (2007), who investigated the SPE of October/November 2003 using their 3-D TIME-GCM, we see that these results are in good qualitative agreement. They show that shortly after the event happened, the southern hemispheric polar region has a decrease in temperature throughout the entire mesosphere, similar to our results for the northern hemispheric polar region. The difference between their results and ours is in the intensity of the changes. For the temperature a decrease of more than $3 \mathrm{~K}$ is shown in this work while Jackman et al. (2007) depict a decrease of up to $2 \mathrm{~K}$. The fact that our results show a larger effect can be due to the intensity of the solar proton event. The Carrington-like event presented in this paper represents an event that is more intense than the SPE of October/November 2003.

The qualitative agreement of our results, modeled with the 3-D CCM SOCOL, for the changes in $\mathrm{NO}_{\mathrm{x}}$, ozone, temperature and dynamics, with those obtained by Thomas et al. (2007) and Jackman et al. (2007), corroborates the finding that solar proton events of this strength have intense atmospheric interactions in a broad altitude range starting from $80 \mathrm{~km}$ down to $30 \mathrm{~km}$, with repercussions for surface air temperature. The latter range from a cooling of up to $5 \mathrm{~K}$ in eastern Europe and Russia to a somewhat smaller decrease of about $3 \mathrm{~K}$ for the Southern Hemisphere in Argentina. Therefore it is important to analyze the impact of energetic particles with a 3-D CCM to ensure that the dynamical and transport aspects are properly taken into account. In this paper, the solar proton event was placed during equinox. We think that the impact could even be larger if it would happen during

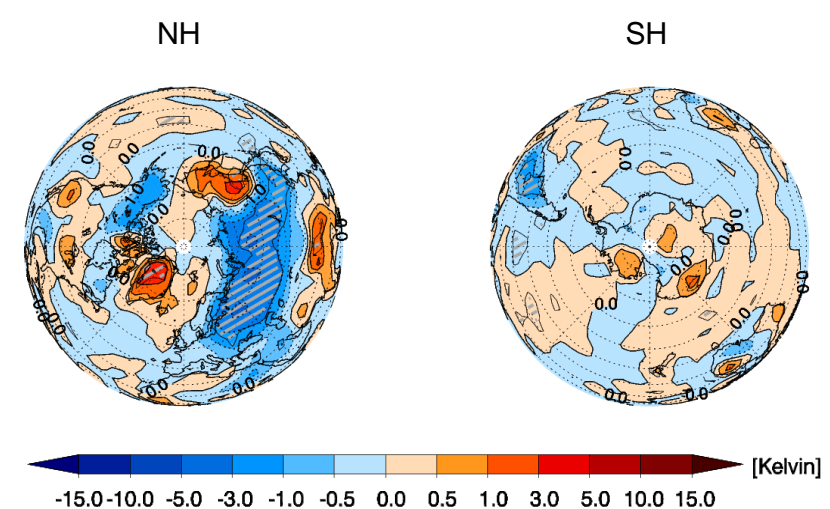

Fig. 9. Left panel: polar stereographic projection of changes in surface air temperature for the $\mathrm{NH}$ for November resulting from the Carrington-like Event. Right panel: same for the SH. Hatched areas show $95 \%$ statistical significance.

earlier winter because the polar vortex prevents the exchange of fresh air from the mid-latitudes with the polar region.

Acknowledgements. MC was partially supported by ETH PolyProject "Variability of the Sun and Global Climate (VSGC)", and ER is partially supported by the Swiss National Science Foundation under grant CRSI122-130642 (FUPSOL). ER also acknowledges useful discussions within the ISSI Teams on "Study of Cosmic Ray Influence upon Atmospheric Processes". MC, PTV and ER would like to thank the International Space Science Institute, Bern, Switzerland for useful discussions within the "Geospace coupling to Polar Atmosphere" team. This work is also part of the ISSI study on "Extreme solar flares as drivers of space weather - from science towards reliable statistics". The work of PTV was supported by the Academy of Finland through the project 136225/SPOC (Significance of Energetic Electron Precipitation to Odd Hydrogen, Ozone, and Climate. Furthermore, ER and PTV are partly supported by COST ES1005 TOSCA (http://www.tosca-cost.eu).

Edited by: W. Ward

\section{References}

Arblaster, J. M. and Meehl, G. A.: Contributions of external forcings to southern annular mode Trends, J. Clim., 19, 2896-2905, 2005.

Barnard, L., Lockwood, M., Hapgood, M. A., Owens, M. J., Davis, C. J., and Steinhilber, F.: Predicting space climate change, Geophys. Res. Lett., 38, L16103, doi:10.1029/2011GL048489, 2011.

Brasseur, G. P. and Solomon, S.:, Aeronomy of the Middle Atmosphere, 3rd edition, Springer, Dordrecht, The Netherlands, 2005

Crutzen, P. J. and Brühl, Ch.: Mass extinctions and supernova explosions, P. Natl. Acad. Sci., 93, 1582-1584, 1996.

Egorova, T., Rozanov, E., Zubov, V., and Karol, I. L.: Model for Investigating Ozone Trends (MEZON), Izvestiya, Atmos. Ocean. Phys., 39, 277-292, 2003.

Egorova, T., Rozanov, E., Zubov, V., Manzini, E., Schmutz, W., and Peter, T.: Chemistry-climate model SOCOL: a validation of 
the present-day climatology, Atmos. Chem. Phys., 5, 1557-1576, doi:10.5194/acp-5-1557-2005, 2005.

Egorova T., Rozanov, E., Ozolin, Y., Shapiro, A., Calisto, M., Peter, Th. and Schmutz, W.: The atmospheric effects of October 2003 solar proton event simulated with the chemistry-climate model SOCOL using complete and parameterized ion chemistry, J. Atmos. Sol. Terr. Phys., 73, 356-365, 2011.

Eyring, V., Butchart, N., Waugh, D. W., Akiyoshi, H., Austin, J., Bekki, S., Bodeker, G. E., Boville, B. A., Bruehl, C., Chipperfield, M. P., Cordero, E., Dameris, M., Deushi, M., Fioletov, V. E., Frith, S. M., Garcia, R. R., Gettelman, A., Giorgetta, M. A., Grewe, V., Jourdain, L., Kinnison, D. E., Mancini, E., Manzini, E., Marchand, M., Marsh, D. R., Nagashima, T., Newman, P. A., Nielsen, J. E., Pawson, S., Pitari, G., Plummer, D.A., Rozanov, E., Schraner, M., Shepherd, T. G., Shibata, K., Stolarski, R. S., Struthers, H., Tian, W., and Yoshiki, M.: Assessment of temperature, trace species, and ozone in chemistry-climate model simulations of the recent past, J. Geophys. Res., 111, D22308, doi:10.1029/2006JD007327, 2006.

Eyring, V., Waugh, D. W., Bodeker, G. E., Cordero, E., Akiyoshi, H., Austin, J., Beagley, S. R., Boville, B. A., Braesicke, P., Bruehl, C., Butchart, N., Chipperfield, M. P., Dameris, M., Deckert, R., Deushi, M., Frith, S. M., Garcia, R. R., Gettelman, A., Giorgetta, M. A., Kinnison, D. E., Mancini, E., Manzini, E., Marsh, D. R., Matthes, S., Nagashima, T., Newman, P. A., Nielsen, J. E., Pawson, S., Pitari, G., Plummer, D.A., Rozanov, E., Schraner, M., Scinocca, J. F., Semeniuk, K., Shepherd, T. G., Shibata, K., Steil, B., Stolarski, R. S., Tian, W., and Yoshiki, M.: Multimodel projections of stratospheric ozone in the 21st century, J. Geophys. Res., 112, D16303, doi:10.1029/2006JD008332, 2007.

Funke, B., Baumgaertner, A., Calisto, M., Egorova, T., Jackman, C. H., Kieser, J., Krivolutsky, A., López-Puertas, M., Marsh, D. R., Reddmann, T., Rozanov, E., Salmi, S.-M., Sinnhuber, M., Stiller, G. P., Verronen, P. T., Versick, S., von Clarmann, T., Vyushkova, T. Y., Wieters, N., and Wissing, J. M.: Composition changes after the "Halloween" solar proton event: the High Energy Particle Precipitation in the Atmosphere (HEPPA) model versus MIPAS data intercomparison study, Atmos. Chem. Phys., 11, 90899139, doi:10.5194/acp-11-9089-2011, 2011.

Jackman, C. H., Roble G. R., and Fleming, E. L.: Mesospheric dynamical changes induced by the solar proton events in October-November 2003, Geophys. Res. Lett., 34, L04812, doi:10.1029/2006GL028328, 2007.

Jackman, C. H., Marsh, D. R., Vitt, F. M., Garcia, R. R., Randall, C. E., Fleming, E. L., and Frith, S. M.: Long-term middle atmospheric influence of very large solar proton events, J. Geophys. Res., 114, D11304, doi:10.1029/2008JD011415, 2009.

Limpasuvan, V., Hartmann, D. L., Thompson, D. L. H., Jeev, K., and Yung, Y. L.: Stratosphere-troposphere evolution during polar vortex intensification, J. Geophys. Res., 110, D24101, doi:10.1029/2005JD006302, 2005.

Manzini, E., McFarlane, N. A., and McLandress, C.: Impact of the Doppler spread parameterization on the simulation of the middle atmosphere circulation using the MA/ECHAM4 general circulation model, J. Geophys. Res. Atmos., 102, 25751-25762, 1997.

McCracken, K. G., Dreschhoff, G. A. M., Zeller, E. J., Smart, D. F., and Shea, M. A.: Solar cosmic ray events for the period 15611994: 1. Identification in polar ice, 1561-1950, J. Geophys. Res.,
106, 21585-21598, 2001.

Porter, H. S., Jackman, C. H., and Green, A. E. S.: Efficiencies for production of atomic nitrogen and oxygen by relativistic proton impact in air, J. Chem. Phys., 65, 154-167, 1976.

Reames, D.V.: Particle acceleration at the Sun and in the heliosphere, Space Sci. Rev., 90, 413-491, 1999.

Rodger, C. J., Verronen, P. T., Clilverd, M. A., Seppälä, A., and Turunen, E.: Atmospheric impact of the Carrington event solar protons, J. Geophys. Res., 113, D23302, doi:10.1029/2008JD010702, 2008.

Rozanov, E., Schlesinger, M. E., Zubov, V., Yang, F., and Andronova, N. G.: The UIUC three-dimensional stratospheric chemical transport model: Description and evaluation of the simulated source gases and ozone, J. Geophys. Res., 104, 1175511781, 1999.

Rusch, D. W., Gerard, J. C., Solomon, S., Crutzen, P. J., and Reid, J. C.: The effect of particle precipitation events on the neutral and ion chemistry of the middle atmosphere I. Odd nitrogen, Planet Space Sci., 29, 767-774, doi:10.1016/0032-0633(81)90048-9, 1981.

Schraner, M., Rozanov, E., Schnadt Poberaj, C., Kenzelmann, P., Fischer, A. M., Zubov, V., Luo, B. P., Hoyle, C. R., Egorova, T., Fueglistaler, S., Brönnimann, S., Schmutz, W., and Peter, T.: Technical Note: Chemistry-climate model SOCOL: version 2.0 with improved transport and chemistry/microphysics schemes, Atmos. Chem. Phys., 8, 5957-5974, doi:10.5194/acp-8-59572008, 2008.

Seppälä, A., Verronen, P. T., Kyrölä, E., Hassinen, S., Backman, L., Hauchecorne, A., Bertaux, J. L., and Fussen, D.: Solar proton event of October-November 2003: Ozone depletion in the Northern Hemisphere polar winter seen by GOMOS/Envisat, Geophys. Res. Lett., 31, L19107, doi:10.1029/2004GL021042, 2004.

Smart, D. F., Shea, M. A., and McCracken, K. G.: The Carrington event: Possible solar proton intensity-time profile, Adv. Space Res., 38, 215-225, 2006.

Solomon, S., Rusch, D. W., Gerard, J.-C., Reidt, G. C., and Crutzen, P. J.: The effect of particle precipitation events on the neutral and ion chemistry of the middle atmosphere: II. Odd Hydrogen, Planet. Space Sci., 29, 885-892, 1981.

Thomas, B. C., Jackman, C. H., and Melott, A. L.: Modeling atmospheric effects of the September 1859 solar flare, Geophys. Res. Lett., 34, L06810, doi:10.1029/2006GL029174, 2007.

Thompson, D. W. J. and Wallace, J. M.: The Arctic Oscillation signature in the wintertime geopotential height and temperature fields, Geophys. Res. Lett., 25, 1297-1300, 1998.

Verronen, P. T., Seppälä, A., Clilverd, M. A., Rodger, C. J., Kyrölä, E., Enell, C.-F., Ulich, Th., and Turunen, E.: Diurnal variation of ozone depletion during the October-November 2003 solar proton events, J. Geophys. Res., 110, A09S32, doi:10.1029/2004JA010932, 2005.

Vitt, F. M., Armstrong, T. P., Cravens, T. E., Dreschhoff, G. A. M., Jackman, C. H., and Laird, C. M.: Computed contributions to odd nitrogen concentrations in the Earth's polar middle atmosphere by energetic charged particles, J. Atmos. Solar-Terr. Phys., 62, 669-683, 2000.

Wolff, E. W., Bigler, M., Curran, M. A., Dibb, J. E., Frey, M. M., Legrand, M., and McConnell, J. R.: The Carrington event not observed in most ice core nitrate records, Geophys. Res. Lett., 39, L08503, doi:10.1029/2012GL051603, 2012. 